\title{
Electronic Balance Application in PM2.5 PM10 Detection
}

\author{
Zhongqi Xiong, Peiying Yu and Yi Su \\ Shanghai Institute of Measurement and Testing Technology
}

\begin{abstract}
In order to research electronic balance application in PM2.5 PM10 particle "weighing method" detection. This article studied operational principle and relative merits of 3 common detection methods including TEOM analytic method, beta-ray analytic method and weighting analytic method for PM2.5 PM10 according to existing standard specifications. And expounded emphatically practical application of electronic balance in PM2.5 PM10 particle "weighing method" detection procedure on aspects of balance selection, environmental requirement and detection operating principle by taking the ultra-micro and micro mass particle detection system. Finally, this article summarizes problems and put forward development direction according to practical application results.
\end{abstract}

Keywords-total suspended particulates (TSP); electronic balance; PM2.5 PM10 weighing method

\section{NECESSITY OF PM2.5 PM10 DETECTION}

Researches show that hazardness of total suspended particulates (TSP) is mainly embodied on two aspects below: On the one hand, the smaller the aerodynamic diameter, the more deeply it enters into respiratory tract. On the other hand, the smaller the aerodynamic diameter, the wider its dispersal range and the larger the influence ranges.

Whereas hazardness of TSP on human and society, it's important to solve PM2.5 PM10 problem. The precondition of pollution control is to detect and measure pollution. How to instantly, accurately, effectively detect their mass concentration has been very urgent and necessary.

\section{CONVENTIONAL MEASURING METHOD OF PM2.5 PM10}

\section{A. Statute Basis}

The "weighing method" and judgment basis of TSP in air are listed in all of Chinese national standards GB15265-1994 Ambient air-Determination of dust-fall-Gravimetric method, HJ618-2011 Determination of atmospheric articles PM10 and PM2.5 in ambient air by gravimetric method and GB176912005 Limits and measurement methods for exhaust pollutants from compression ignition and gas fuelled positive ignition engines of vehicles (III, IV, V). With China gradually attaching importance to inhalable particle PM2.5 in recent years, Chinese new edition GB 3095-2012 Ambient Air Quality Standards increases the concentration limitation for particulate matter ( particle size less than or equal to $2.5 \mu \mathrm{m}$ ) and specifies PM2.5 analytic methods: namely TEOM, beta-ray method and weighing method[4].

\section{B. Comparison for Multifold Measuring Methods}

TABLE I. ADVANTAGES AND DISADVANTAGES FOR ANALYTICAL PRINCIPLE AND ANALYTIC PROCESS OF PM2.5 DETECTION METHODS

\begin{tabular}{|c|c|c|c|}
\hline $\begin{array}{l}\text { Measurin } \\
\text { g method }\end{array}$ & $\begin{array}{l}\text { Weighing } \\
\text { method }\end{array}$ & TEOM & $\begin{array}{c}\text { Beta-ray } \\
\text { method }\end{array}$ \\
\hline $\begin{array}{l}\text { Operating } \\
\text { principle }\end{array}$ & $\begin{array}{c}\text { Use a } \\
\text { balance to } \\
\text { weigh the } \\
\text { sample } \\
\text { mass on the } \\
\text { sampling } \\
\text { membrane } \\
\text { under } \\
\text { constant } \\
\text { temperature } \\
\text { and } \\
\text { humidity } \\
\text { conditions, } \\
\text { calculate } \\
\text { particulate } \\
\text { matter } \\
\text { concentrati } \\
\text { on in air by } \\
\text { combining } \\
\text { with } \\
\text { sampling } \\
\text { flow-rate. }\end{array}$ & $\begin{array}{l}\text { Use a quartz hollow } \\
\text { taper pipe in mass } \\
\text { sensor, place a } \\
\text { replaceable filter } \\
\text { membrane at the } \\
\text { oscillation end of the } \\
\text { hollow taper pipe, } \\
\text { utilize the feature that } \\
\text { oscillation frequency } \\
\text { changes along with } \\
\text { filter membrane mass, } \\
\text { figure out particulate } \\
\text { matter mass deposited } \\
\text { on filter membrane by } \\
\text { measuring variance in } \\
\text { oscillation frequency. }\end{array}$ & $\begin{array}{c}\text { Detect variance } \\
\text { in atmosphere } \\
\text { particulate } \\
\text { matter mass by } \\
\text { utilizing } \\
\text { variance in beta- } \\
\text { ray attenuation } \\
\text { value released } \\
\text { by particulate } \\
\text { matter deposited } \\
\text { on quartz filter } \\
\text { membrane for } \\
\text { Carbon- } 14 .\end{array}$ \\
\hline Advantage & $\begin{array}{c}\text { High } \\
\text { measuring } \\
\text { accuracy } \\
\text { with statute } \\
\text { basis, } \\
\text { generally } \\
\text { used as } \\
\text { calibration } \\
\text { method in } \\
\text { automatic } \\
\text { analysis } \\
\text { method. } \\
\end{array}$ & $\begin{array}{c}\text { Quantitative relation is } \\
\text { explicit }\end{array}$ & Fast, convenient \\
\hline $\begin{array}{l}\text { Disadvant } \\
\text { age }\end{array}$ & $\begin{array}{c}\text { It needs to } \\
\text { correctly } \\
\text { select a } \\
\text { balance. It } \\
\text { is higher in } \\
\text { laboratory } \\
\text { environmen } \\
\text { t } \\
\text { requiremen } \\
\text { t. }\end{array}$ & $\begin{array}{l}\text { The existing } \\
\text { technology cannot } \\
\text { solve loss of volatile } \\
\text { and half-volatile } \\
\text { matters after sample } \\
\text { heating, result in that } \\
\text { determination result is } \\
\text { deemed to be on the } \\
\text { low side. }\end{array}$ & $\begin{array}{c}\text { The systematic } \\
\text { error exists in } \\
\text { determination } \\
\text { data. The failure } \\
\text { rate is low in a } \\
\text { relatively clean } \\
\text { and dry region, } \\
\text { but very high in } \\
\text { a moist and high } \\
\text { temperature } \\
\text { region. }\end{array}$ \\
\hline
\end{tabular}

The detection methods for TSP in air are multifarious. According to nature of TSP, analytical principle can be divided into multifold different methods. If measurement for PM2.5 is 
exampled, the measuring methods are divided into two main classes: automatic analysis and manual analysis. Therein, the automatic analysis method contains TEOM and beta-ray method. The manual analysis method mainly means the weighing method. The advantages and disadvantages on analytical principle and analytic process of above 3 methods are shown in Table I.

It can be seen from Table I that TEOM and beta-ray method as automatic analysis method are relatively simple and convenient in operation mode and can be used for onsite fast detection. But systematic error exists in the weighing process, so detection accuracy is not high. The weighing method as manual analysis method is to compare mass difference before/after sampling on high precision electronic balance within specified sampling time under constant temperature and humidity laboratory conditions. In whole measuring process, most of factors influential on measurement result can be actually measured and corrected, so the method is relatively higher in measuring accuracy. In measurement procedure of TSP, the weighing method is generally available for calibration for instruments with automatic analysis method.

\section{ELECTRONIC BALANCE APPLICATION IN PM2.5 PM10 WEIGHING METHOD DETECTION}

\section{A. Electronic Balance Selection In Pm2.5 Pm10 Weighing Method Detection}

It is specified in HJ618-2011 Determination of atmospheric articles PM10 and PM2.5 in ambient air by gravimetric method that it needs to select an analytical balance with verification scale interval (e) of $0.1 \mathrm{mg}$ or $0.01 \mathrm{mg}$ [5].

According to electronic balance used in weight method measurement for automobile exhaust contamination PM2.5 PM10 in GB17691-2005 Limits And Measurement Methods For Exhaust Pollutants From Compression Ignition And Gas Fuelled Positive Ignition Engines Of Vehicles (III, IV, V), its standard deviation shall not be greater than $2 \mu \mathrm{g}$ [2]. Thus it can be seen that only level I electronic balance with actual scale interval (d) below $0.01 \mathrm{mg}$ meets weighting requirements of PM2.5 PM10 in ambient air by contrasting Table of Electronic Balance Metering Performance ( as shown in Table II) in JJG1036 - 2008 Electronic Balance Calibration Procedure.

\section{TABLE II. LEVEL I ELECTRONIC BALANCE'S METERING} PERFORMANCE

\begin{tabular}{|c|c|}
\hline $\begin{array}{c}\text { Verification } \\
\text { scale interval } \\
\text { (e) }\end{array}$ & \multirow{2}{*}{$\begin{array}{c}\text { Minimal } \\
\text { weighing }\end{array}$} \\
\cline { 1 - 1 } $1 \mathrm{~g} \leq \mathrm{e}<1 \mathrm{mg}$ & \multirow{2}{*}{$100 \mathrm{e}$} \\
\cline { 1 - 1 } $1 \mathrm{mg} \leq \mathrm{e}$ & \\
\hline
\end{tabular}

\begin{tabular}{|c|c|c|}
\hline $\begin{array}{c}\text { Actual } \\
\text { scale } \\
\text { interval } \\
\text { (d) }\end{array}$ & $\begin{array}{c}\text { Verification } \\
\text { scale } \\
\text { interval } \\
(\mathbf{e}=\mathbf{1 0 d})\end{array}$ & $\begin{array}{c}\text { Minimal } \\
\text { weighing }\end{array}$ \\
\hline $0.1 \mathrm{~g}$ & $1 \mathrm{~g}$ & $0.1 \mathrm{mg}$ \\
\hline $1 \mathrm{~g}$ & $0.01 \mathrm{mg}$ & $1 \mathrm{mg}$ \\
\hline $0.01 \mathrm{mg}$ & $0.1 \mathrm{mg}$ & $10 \mathrm{mg}$ \\
\hline
\end{tabular}

In addition, according to national standard, the minimal load of filter paper shall be $0.065 \mathrm{mg} / 1000 \mathrm{~mm} 2$ filter paper area. The minimal load of filter paper with the most common size in China is shown in Table III. According to JJG10362008 Electronic Balance Calibration Procedure, electronic balance ensures measurement characteristic only between minimal weighing Min and maximal weighing Max [1].

It can be seen from Table III. that if PM2.5 or even smaller air particulate matter is weighed, its mass must be weighed on Level I electronic balance with actual scale interval (d) of 0.1 $\mathrm{mg}$ under condition meeting the fact that minimal load is greater than minimal weighing of the balance .

TABLE III. MINIMAL LOAD OF FILTER PAPER WITH THE MOST COMMON SIZE

\begin{tabular}{|c|c|c|c|c|}
\hline $\begin{array}{c}\text { Filter } \\
\text { paper } \\
\text { diameter / } \\
\text { (mm) }\end{array}$ & 47 & 70 & 90 & 110 \\
\hline $\begin{array}{c}\text { Minimal } \\
\text { load / (mg) }\end{array}$ & 0.11 & 0.25 & 0.41 & 0.6 \\
\hline
\end{tabular}

B. Electronic Balance's Application in PM2.5 PM10 Weighing Method Detection

Along with improvement of electronic balance accuracy, more and more high accuracy electronic balance, especially electronic balance with $\mathrm{e}<1 \mathrm{mg}$ is applied to detection procedure of ambient air weighing method. These high accuracy electronic balances are high in accuracy, so they are higher in requirements on laboratory environment, personnel and data processing during emplacement and operation. Shanghai Institute of Measurement and Testing Technology, according to service experience of high precision electronic balance and detection ability for air environment, newly builds ultra-micro and micro mass particle detection system and take the lead in applying the millionth and ten-millionth balances to detection and analysis of TSP in air. This article concretely expounds the high accuracy electronic balance application in PM2.5 PM10 weighing method detection on aspects of systemic operating principle, technology index and environmental requirement.

1) Operating principle for detection system of ultramicro and micro mass particles

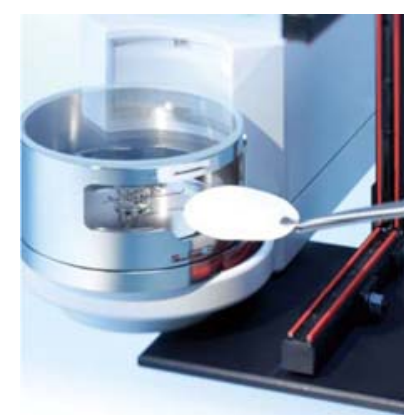

FIGURE I. SCHEMATIC DIAGRAM DURING WEIGHING OF SYSTEM

Ultra-micro and micro mass particles are very tiny and difficult of single acquisition and weighing, so it must be detected by dint of filter membrane as carrier (as shown in Figure I). According to difference in particulate matter's aerodynamic diameters and sampling frequency as well as environment, the diameters of filter papers used for carrying it are different. Different filter paper sizes need to be matched with the mass comparator with corresponding scale pan size. In 
addition, micro mass particles are different in sizes and hazardness, so detective accuracy requirements are also different. Via investigation, Shanghai Institute sets 2 kinds of electronic balances with diameters of $0.1 \mu \mathrm{g}$ and $1 \mu \mathrm{g}$ in system, thereby meeting detection demands for different diameter mass particles between $1 \mu \mathrm{g}$ and $1 \mathrm{mg}$.

The environment sampling department selects corresponding filter membrane (see Table III) according to aerodynamic diameter size and minimal load of sampling particulates. For instance: $\phi 47 \mathrm{~mm}$ and $\phi 70 \mathrm{~mm}$ are used generally for PM5; $\phi 110 \mathrm{~mm}$ and $\phi 150 \mathrm{~mm}$ are used generally for filter membrane diameter of automobile exhaust gas contamination detection. After filter membrane is designated, the filter membrane is placed on electronic balance with corresponding accuracy rate for weighing. For instance: PM2.5 and PM5 sampling filter membranes are detected on electronic balance with actual scale interval of $0.1 \mathrm{ug}$, while PM10 sampling filter membrane is detected on electronic balance with actual scale interval of lug. After weighing finishes, record initial mass value $\mathrm{m}_{0}$ of filter membrane. Afterwards, the environment sampling department places the filter membrane in a sampler for sampling, after which it places the filter membrane on electronic balance with corresponding accuracy rate for weighing, records mass value $\mathrm{ml}$ at this moment, and according to Equation (1), figure out mass concentration of TSP in each cubic meter air.

$$
R=\frac{\mathrm{m}_{1}-\mathrm{m}_{0}}{Q \times t} \times 1000 \quad \mathrm{mg} / \mathrm{m}^{3}
$$

Wherein:

$\mathrm{R}-$ Mass concentration of total suspended particulate in air

$\mathrm{m}_{0}$ _ Filter membrane mass before sampling

$\mathrm{m}_{1}$ — Filter membrane mass after sampling

Q_Air flow-rate during sampling

$\mathrm{t}$ - Sampling time

2) Technology Indices for Detection System of UltraMicro and Micro Mass Particles

According to the above operating principle, concrete technology indices of ultra-micro and micro mass particulate detection system are shown in Table IV. By conducting subsystem weighing processing in detection procedure of PM2.5 PM10 weighing method, it not only conducts the distinguishing detection for PM2.5 PM10, but also solves problems that weighing accuracy, minimal weighing scope and scale pan size and other requirements are inconsistent in detection procedure of PM2.5 PM10 weighing method. The subsystem weighing processing not only improves delectability of PM2.5 and even smaller suspended particulates, but also solves the problem that $0.1 \mu \mathrm{g}$ scale pan cannot meet weighing requirements of PM10 filter membrane. Via analysis for uncertainty, the uncertainty of ultra-micro particulate mass detection in system can be controlled in $0.5 \mu \mathrm{g}$. The uncertainty of micro particulate mass detection can be controlled in $10 \mu \mathrm{g}$.

TABLE IV. TECHNOLOGY INDICES FOR DETECTION SYSTEM OF ULTRA-MICRO AND MICRO MASS PARTICLES

\begin{tabular}{|c|c|c|}
\hline System classification & $\begin{array}{c}\text { Ultra-micro } \\
\text { mass particulate }\end{array}$ & Micro mass particulate \\
\hline Weighing scope & $\leq 6 \mathrm{~g}$ & $\leq 50 \mathrm{~g}$ \\
\hline $\begin{array}{c}\text { Actual scale interval } \\
\text { ( d) }\end{array}$ & $0.1 \mu \mathrm{g}$ & $1 \mathrm{~g}$ \\
\hline Repetitiveness & $0.15 \mu \mathrm{g}$ & $3 \mu \mathrm{g}$ \\
\hline Linearity & $\pm 1 \mu \mathrm{g}$ & $\pm 10 \mu \mathrm{g}$ \\
\hline $\begin{array}{c}\text { Applicable filter } \\
\text { membrane size }\end{array}$ & $\leq \phi_{70 \mathrm{~mm}}$ & $\phi_{70 \mathrm{~mm} \sim} \phi_{150 \mathrm{~mm}}$ \\
\hline
\end{tabular}

3) Environmental Requirements for Detection System of Ultra-micro and Micro Mass Particles

According as JJG1036-2008 Electronic Balance Calibration Procedure, Level I electronic balances with actual scale interval (d) below $0.01 \mathrm{mg}$ is provided with environmental requirements of normal working in laboratory. When such balances, especially $0.1 \mu \mathrm{g}$ and $1 \mu \mathrm{g}$ electronic balances, are applied to mass concentration detection of TSP in ambient air, the higher requirements are put forward for in-house ambient conditions of the environment detection laboratory. When $0.1 \mu \mathrm{g}$ and $1 \mu \mathrm{g}$ electronic balances are exampled, ambient conditions during normal working are shown in Table v:

TABLE V. AMBIENT CONDITION DURING NORMAL WORKING OF 0.1MG AND 1MG ELECTRONIC BALANCES

\begin{tabular}{|c|c|}
\hline Temperature fluctuation & $\leq 0.5^{\circ} \mathrm{C} / 4 \mathrm{~h}$ \\
\hline Humidity & $\begin{array}{c}30 \%-70 \%, \text { Fluctuation } \leq 10 \% / 4 \\
\mathrm{~h}\end{array}$ \\
\hline Wind speed & $\leq 0.3 \mathrm{~m} / \mathrm{s}$ \\
\hline Vibration frequency & $\leq 0.5 \mathrm{mg}$ \\
\hline
\end{tabular}

If the laboratory cannot reach normal working conditions of electronic balance, an independent weighing area can be set for electronic balance, thereby meeting accuracy requirements of measuring PM2.5 or even smaller suspended particulates. For mass measurement of some ultra-micro particulate matters, it also needs to add a destaticizing device in measuring process to prevent static electricity from affecting detection result. In addition to this, improving laboratory cleanliness or sealing the filter membrane in corresponding container for weighing can prevent the filter membrane from suffering secondary pollution of detection environment in weighing process, thereby improving detective accuracy.

In one word, only under a satisfactory environment, can electronic balance normally work. Only when detection interference source is evaded as far as possible, can the measuring accuracy be ensured for PM2.5 PM10 weighing method detection.

\section{PROBlEMS IN APPLICATION AND FUTURE IMPROVEMENT DIRECTION}

Along with technological progress, electronic balance is gradually replacing mechanical balance and is more widely 
applied to ambient air detection. Electronic balance is characterized by high accuracy, fast display, convenient and quick operation and other advantages. However, the following problems also exist in practical application of electronic balance:

\section{A. $0.1 \mathrm{mg}$ and $1 \mathrm{mg}$ Electronic Balances' High Sensitivity for Environment Affects Detection results}

Even in the mass metering field, ambient conditions for normal working of $0.1 \mathrm{mg}$ and $1 \mathrm{mg}$ electronic balances are also very harsh. In detection procedure of ambient air quality, the weighing method obtains mass value of PM2.5 PM10 suspended particulates by comparing mass difference before/after filter membrane sampling. Therefore it has very high requirement for balance's reproducibility. $0.1 \mathrm{mg}$ and $1 \mathrm{mg}$ electronic balance's high sensitivity for peripheral environment makes electronic balance display value change along with environmental change, thereby introducing electronic balance's error into detective results of PM2.5 PM10 weighing method and affecting result accuracy.

\section{B. Electronic Balance with Actual Scale Interval (d) Below $0.01 \mathrm{mg}$ is Difficult of Tracing to the Source.}

The calibration certificate is mostly issued for Level I electronic balance below $0.01 \mathrm{mg}$ by referring to JJF1326-2011 Calibration Specification for Mass Comparators. In calibration process, we generally only pay close attention to repetitiveness and expansion uncertainty during Max/2 and Max. In detection procedure of PM2.5 PM10 weighing method, direct reading of the balance is adopted for all of weighing, so there are very high requirements for indication error, unbalance loading and repetitiveness and other metering performances within range of balance's full scale. How to calibrate these hundred thousandth, millionth even ten-millionth electronic balances by referring to JJG1036-2008 Electronic Balance Calibration Procedure is the problem confronted by all levels of metering organizations.

It is an inevitable result in detection technique development for electronic balance to enter into PM2.5 PM10 detection procedure. Establishment of ultra-micro and micro mass detection system verifies feasibility of electronic balance application in PM2.5 PM10 detection procedure again by example.

Whereas problems in application, in research and development in future, development shall be improved by reducing electronic balance's sensitivity for environment and improving environmental stability, traceability method and others technology means, thereby ensuring that Level I electronic balance can be more comprehensively applied to ambient air detection and can serve for environmental protection undertaking.

\section{REFERENCES}

[1] JJG1036-2008 Electronic Balance Calibration Procedure, China Metrology Publishing House

[2] GB17691-2005 Limits and measurement methods for exhaust pollutants from compression ignition and gas fuelled positive ignition engines of vehicles (III, IV, V), China Environmental Science Press
[3] GB/T15265-1994 Ambient air-Determination of dust-fall-Gravimetric method, China Environmental Science Press

[4] GB3095-2012 Ambient air quality standards, China Metrology Publishing House

[5] HJ618 - 2011 Determination of atmospheric articles PM10 and PM2.5 in ambient air by gravimetric method, China Metrology Publishing House

[6] Wenzhong Dong, "Weighing uncertainty of PM2.5 by the weighting method ", The 17th seminar on control technique of sulfur dioxide nitric oxides and control and monitoring technology of mercury pollution and fine particulate matter ( PM2.5)

[7] RTI (Research Triangle Institute) Standard Operation Procedure for Particulate Matter (PM) Gravimetric Analysis July 8,2008

[8] NAREL (National Air and Radiation Environment Laboratory) Standard Operation Procedure Gravimetric Mass Measurements for the PM2.5 Chemical Speciation QA Program AM/SOP-19, Effective May 23,2011 